\title{
A systematic review and meta-analysis of tertiary interventions in clinical burnout
}

\begin{abstract}
Clinical burnout is one of the leading causes of work absenteeism in high- and middle-income countries. There is hence a great need for the identification of effective intervention strategies to increase return-to-work (RTW) in this population. This review aimed to assess the effectiveness of tertiary interventions for individuals with clinically significant burnout on RTW and psychological symptoms of exhaustion, depression and anxiety. Four electronic databases (Ovid MEDLINE, PsychINFO, PubMed and CINAHL Plus) were searched in April 2016 for randomised and non-randomised controlled trials of tertiary interventions in clinical burnout. Article screening and data extraction were conducted independently by two reviewers. Pooled odds ratios (ORs) and hazard ratios (HRs) were estimated with random-effects meta-analyses. Eight articles met the inclusion criteria. There was some evidence of publication bias. Included trials were of variable methodological quality. A significant effect of tertiary interventions compared with treatment as usual or wait-list controls on time until RTW was found, $\mathrm{HR}=4.5,95 \%$ confidence interval $(\mathrm{CI})=2.15-9.45$; however, considerable heterogeneity was detected. The effect of tertiary interventions on full RTW was not significant, $\mathrm{OR}=1.33,95 \% \mathrm{CI}$ $=0.59-2.98$. No significant effects on psychological symptoms of exhaustion, depression or anxiety were observed. Tertiary interventions for individuals with clinically significant burnout may be effective in facilitating RTW. Successful interventions incorporated advice from labour experts and enabled patients to initiate a workplace dialogue with their employers.
\end{abstract}


Keywords: clinical burnout, exhaustion, tertiary interventions, return-to-work, systematic review, meta-analysis

Manuscript Word Count: 5,244

\section{Introduction}

Stress-related psychological ill-health is the leading cause of work absenteeism in the Organisation for Economic Co-operation and Development (OECD) countries (OECD, 2012, 2013). The estimated cost of work-related stress in the European Union approximates $€ 20$ billion annually (European Agency for Safety and Health at Work, 2014). Notwithstanding a few important conceptual dissimilarities, most available definitions of "burnout" highlight exhaustion as a core symptom (see Grossi, Perski, Osika, \& Savic, 2015 for a review of different conceptualisations of burnout). It has been proposed that a distinction should be made between a milder form of burnout, which implicates symptoms that do not fully incapacitate the employee, and "clinical burnout", which implies clinically significant exhaustion and impaired work performance, which motivates professional care-seeking (Schaufeli, Bakker, Hoogduin, Schaap, \& Kladler, 2001). The present review focuses on "clinical burnout" as defined by Schaufeli and colleagues (2001).

Due to the large organisational and societal costs of stress-related work absenteeism, there is a great need to identify interventions that are effective in increasing return-to-work (RTW) in this population. Tertiary interventions refer to interventions that focus on the treatment of individuals who fulfill the diagnostic criteria for stress-related disorders and the facilitation of RTW, as opposed to primary or secondary interventions, which focus on the prevention of disease incidence and progression, respectively (Maslach \& Goldberg, 1998). Tertiary 
interventions may be delivered at the individual or organisational level. While individual-level interventions typically include elements of cognitive behavioural therapy (CBT), relaxation training, meditation, or physical activity, organisational interventions typically focus on organisational re-structuring and leadership training (Maslach \& Goldberg, 1998).

Although not empirically explored, it may be hypothesised that the effect of tertiary interventions on RTW is mediated by reduced symptoms of exhaustion, depression and anxiety. Whether or not depression and/or anxiety should be regarded as symptoms or correlates of clinical burnout is disputed in the literature (Åsberg, Nygren, \& Nager, 2013; Bianchi, Sam, \& Laurent, 2015; Leiter \& Durup, 1994; Richardsen et al., 1992); however, elevated levels of depression and anxiety are often reported in this patient group (Åsberg et al., 2013; Bianchi et al., 2015; Richardsen et al., 1992). Although the direction of influence is yet to be determined (e.g. depression and anxiety may predispose individuals to develop clinical burnout, or clinical burnout may itself give rise to depression and anxiety), these conditions are themselves implicated in stress-related work absenteeism (OECD, 2012, 2013) and hence, merit investigation in return-to-work interventions.

Existing reviews of tertiary interventions have typically not focused solely on clinical burnout. For example, Franche and colleagues conducted a systematic review to assess the effectiveness of workplace interventions for individuals on sickleave due to musculoskeletal or other pain-related conditions. They found that time until RTW was significantly reduced in interventions that provided work accommodation offers, contact between healthcare provider and workplace, ergonomic worksite visits and the presence of an RTW coordinator (Franche et al., 
2005). A review of interventions for different kinds of work disabilities (e.g. musculoskeletal disorders, clinical burnout) was unable to draw any conclusions regarding the effect on work absenteeism due to the scarcity of studies (van Oostrom et al., 2009).

On the other hand, existing reviews of interventions for clinical burnout have not included or were unable to estimate effects on RTW. For example, Montano and colleagues assessed the effectiveness of organisational-level workplace interventions on employees' health (e.g. ischemic heart disease risk, clinical burnout, back pain) but did not focus on time until RTW (Montano, Hoven, \& Siegrist, 2014). Richardson and Rothstein conducted a meta-analysis of the effectiveness of stressmanagement interventions in occupational settings but did not assess time until RTW (Richardson \& Rothstein, 2008). A recently published systematic review of tertiary interventions for individuals with a diagnosis of burnout was unable to assess the pooled effect of interventions on RTW due to an insufficient sample size (Ahola, Toppinen-Tanner, \& Seppänen, 2017).

As clinical burnout is one of the main causes of work absenteeism in high- and middle-income countries, there is a great need for studies that identify effective intervention strategies. Therefore, the primary aim of this review was to systematically review the literature to assess the effect of tertiary interventions for individuals with clinical burnout on RTW. A secondary aim was to assess the effectiveness of these interventions on psychological symptoms of exhaustion, depression and anxiety. 


\section{Methods}

\section{Criteria for considering studies for this review}

Types of studies. Randomised controlled trials (RCTs) and non-randomised controlled trials with a matched control group were considered for inclusion. Studies had to be written in English.

Types of participants. Studies that recruited adults aged 18 or over with a diagnosis of clinical burnout, exhaustion disorder, adjustment disorder or a stressrelated mental disorder were included. No upper age limit was imposed.

Types of interventions. We included trials that compared a "psychosocial intervention' for stress-related mental disorders or clinical burnout, delivered either individually or in groups, with a wait-list control or treatment as usual (TAU). A 'psychosocial intervention' is defined here as any intervention focusing on psychological (e.g. health education, coping skills, mental relaxation) or social factors (e.g. social skills training) as opposed to biological factors, such as medication (Ruddy \& House, 2005). Studies with follow-up assessments conducted within 24 months' post-intervention were considered for inclusion. Where more than two intervention groups were compared, individual as opposed to group-based treatments were favoured, as were wait-list controls as opposed to TAU. 
Types of outcome measures. The primary outcome was return-to-work (RTW) operationalised as days until RTW (i.e. continuous variable) or full RTW at followup (i.e. categorical variable). Secondary outcomes included (i) exhaustion, as measured by self-report or observational scales such as the Maslach Burnout Inventory-General Survey (MBI-SG; Schutte, Toppinen, Kalimo, \& Schaufeli, 2000) or the Shirom-Melamed Burnout Questionnaire (SMBQ; Shirom \& Melamed, 2006); (ii) depression, as measured by self-report or observational scales such as the Hospital Anxiety and Depression Scale (HADS; Bjelland, Dahl, Haug, \& Neckelmann, 2002; Zigmond \& Snaith, 1983); and (iii) anxiety, as measured by selfreport or observational scales such as the HADS.

\section{Search methods for identification of studies}

Electronic searches. The following electronic databases were searched in April 2016: MEDLINE (via Ovid), PsychINFO (via Ovid), PubMed and CINAHL Plus. No limitations regarding time frame were applied. Free text or index terms (e.g. Medical Subject Headings) were searched for in titles and abstracts (see Supplementary Material 1). Due to the lack of consensus regarding the terminology used to describe the diagnosis of interest, we used a broad range of search terms including 'clinical burnout', 'exhaustion disorder', 'adjustment disorder' and 'stressrelated mental disorder' to increase the possibility of finding all relevant trials on the topic.

Other sources. Additional articles of interest were identified through expertise within the review team and through backward and forward reference chaining (Centre for Reviews and Dissemination, 2008). 


\section{Data collection and analysis}

Selection of studies. Identified articles were merged using EndNote X7

(Thomson Reuters, 2013) to ensure consistency. Duplicate records were removed.

Two reviewers independently screened (i) titles, (ii) abstracts and (iii) full texts against the eligibility criteria (The Cochrane Collaboration, 2011). Any

disagreements were resolved through discussion, and through consulting a third reviewer if necessary.

Data extraction and management. Data on study setting, study design, sample characteristics, intervention content, intervention duration, intervention intensity and outcome measures were independently extracted by two reviewers. Any disagreements were resolved through discussion, and through consulting a third reviewer if necessary.

Assessment of risk of bias in included studies. The methodological quality of included studies was assessed using the Cochrane Collaboration's tool for assessing risk of bias (The Cochrane Collaboration, 2011), which recommends assessing the following domains: sequence generation and allocation concealment (selection bias), blinding of participants and providers (performance bias), blinding of outcome assessors (detection bias), incomplete outcome data (attrition bias), selective outcome reporting (reporting bias) and other sources of bias.

Publication bias. Data from the included studies were entered into a funnel plot, plotting the size of studies against their respective effect sizes, to assess the possibility of publication bias (Egger, Davey Smith, Schneider, \& Minder, 1997). 


\section{Measures of treatment effect}

Data synthesis. Review Manager 5.0. (The Nordic Cochrane Centre: The Cochrane Collaboration, 2008) was used for the data synthesis. For binary outcomes (i.e. RTW at follow-up), the Mantel-Haenszel method for calculating odds ratios (ORs) was used. For time-to-event data (i.e. days until RTW), the O-E method for calculating hazard ratios (HRs) was used. For continuous outcomes (i.e. exhaustion, depression, anxiety), the weighted mean difference (WDM) or standardised mean difference (SMD) were calculated, as appropriate. The SMD was calculated when outcomes had been measured using different scales. Where intention-to-treat (ITT) data were not available, data from complete-case analyses were used. Where outcomes had been measured more than once, data from the longest follow-up assessment were used.

Assessment of heterogeneity. Statistical heterogeneity was assessed using the $\mathrm{I}^{2}$ statistic, which assesses the proportion of variance between studies caused by clinical and methodological differences, as opposed to that caused by chance (The Cochrane Collaboration, 2011). While clinical heterogeneity may arise from causes such as different intervention content and duration, different treatment settings, and group versus individual treatment, methodological heterogeneity may arise from causes such as different study designs and different degrees of bias.

\section{Results}

\section{Description of studies}

A total of 301 published articles were identified through the literature search. After removing duplicates, 244 articles remained for screening. Of the 16 full-texts 
screened, eight met the inclusion criteria and were included in the quantitative synthesis (see Figure 1).

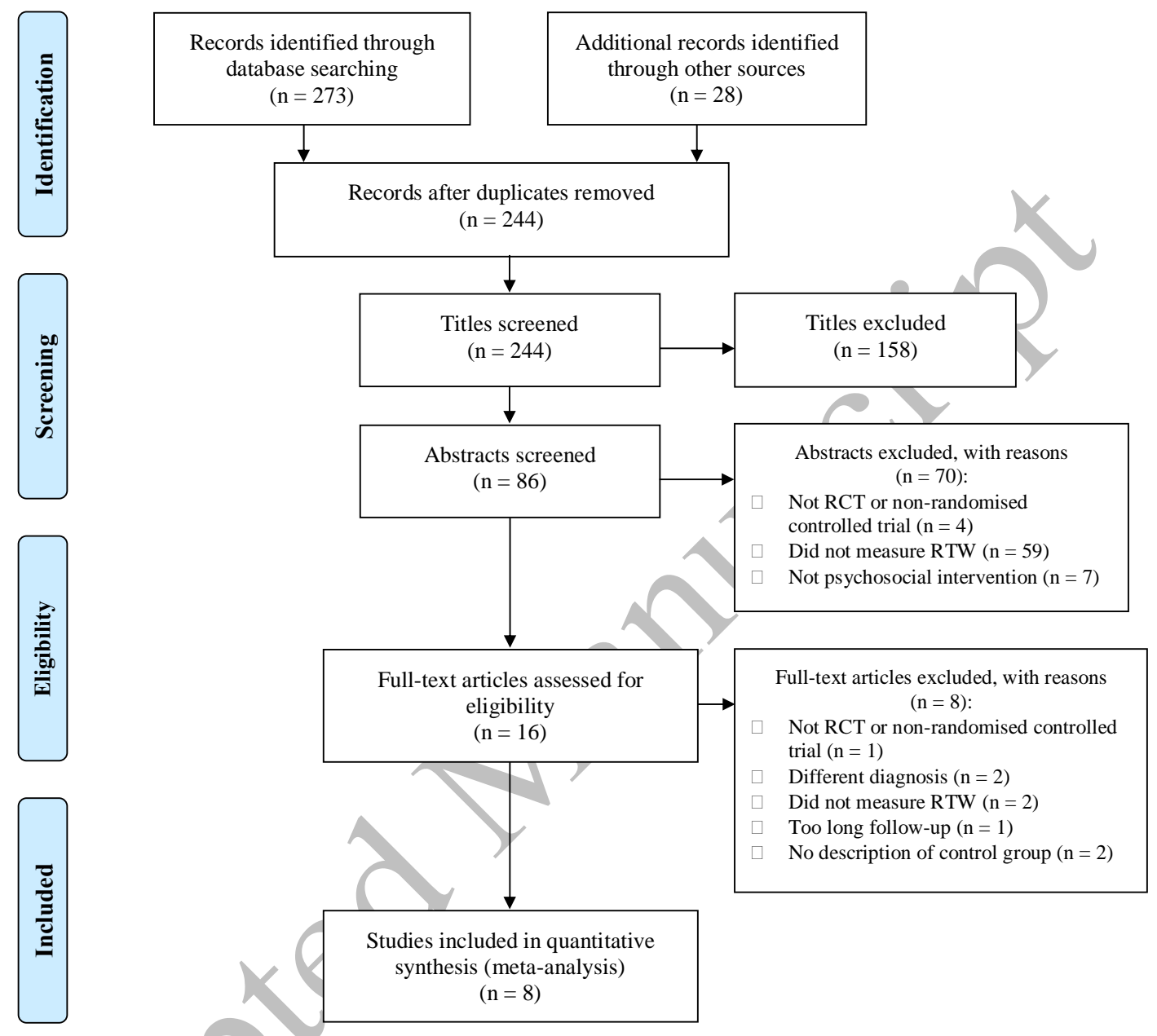

Figure 1. PRISMA flow diagram of study selection process (Moher, Liberati,

Tetzlaff, \& Altman, 2009).

\section{Study and participant characteristics}

All of the reviewed studies were conducted in Northern Europe (i.e. the Netherlands, Denmark, Sweden) and included a total of 1,192 participants (see Table 1). The average age of participants ranged from 39.5 to 46.0 years (see Table 2). In most studies, females were overrepresented. The study by Blonk, Brenninkmeijer, Lagerveld and Houtman (2006) was an exception with more men than women 
participating. Participants were moderately to highly educated (i.e. post-16 qualifications or above). The majority of studies were conducted in a primary care setting, with the exception of Stenlund et al. (2009) and Willert, Thulstrup and Bonde (2011), which were conducted in a secondary care setting. Five studies employed an RCT design with either 2 (Stenlund et al., 2009; Willert et al., 2011) or 3 (Blonk et al., 2006; de Vente, Kamphuis, Emmelkamp, \& Blonk, 2008; Netterstrøm, Friebel, \& Ladegaard, 2013) treatment arms. One study used a clusterRCT design with two arms (Bakker et al., 2007). The remaining two studies used a non-randomised controlled trial design with a matched control group (Eklund \& Erlandsson, 2011; Lander, Friche, Tornemand, Andersen, \& Kirkeskov, 2009).

\section{Intervention characteristics and effects}

Although all of the included studies compared a tertiary intervention with TAU or a wait-list control, the content of interventions varied extensively (see Table 2). Commonly employed intervention components included psychoeducation (Blonk et al., 2006; de Vente et al., 2008; Lander et al., 2009; Stenlund et al., 2009; Willert et al., 2011), relaxation and mindfulness training (Blonk et al., 2006; de Vente et al., 2008; Netterstrøm et al., 2013; Stenlund et al., 2009), time management training (Blonk et al., 2006; de Vente et al., 2008) and the development of coping strategies (Netterstrøm et al., 2013; Stenlund et al., 2009). Four studies explicitly stated that their intervention was based on CBT (Blonk et al., 2006; de Vente et al., 2008; Stenlund et al., 2009; Willert et al., 2011). Less commonly reported intervention components included assertiveness skills training (de Vente et al., 2008), advice from labour experts (Blonk et al., 2006) and the enablement of a workplace dialogue (Netterstrøm et al., 2013). The support provided to control groups varied or was not 
reported; participants were typically offered a limited number of face-to-face meetings with a general practitioner or an occupational therapist (Bakker et al., 2007; Blonk et al., 2006; de Vente et al., 2008; Eklund \& Erlandsson, 2011).

The duration and intensity of interventions varied extensively. In the study by Bakker et al. (2006), patients received a brief intervention whenever they visited their general practitioner (GP). No superior effect of the brief intervention on RTW was detected. Patients in the studies by Blonk et al. (2006) and de Vente et al. (2008) were offered 11 and 12 sessions, respectively. Although a significant effect on RTW was observed in Blonk et al. (2006), no significant group differences were detected in de Vente et al. (2008). Patients in the study by Lander et al. (2009) were offered 4-5 treatment sessions. A non-significant effect on full RTW was observed. In the study by Eklund and Erlandsson (2011), patients were offered two weekly 2.5-hour sessions over a period of 10 weeks, followed by a 6-week work placement. A superior effect on full RTW was observed. In the study by Netterstrøm et al. (2013), patients were offered 8 sessions over a period of 12 weeks in addition to 8 sessions of mindfulness training. Similarly, the study by Willert et al. (2011) offered patients 8 sessions over a period of 12 weeks. A significant effect on full RTW was detected in both Netterstrøm et al. (2013) and Willert et al. (2011). In contrast, the study by Stenlund et al. (2009) offered patients 30 sessions over a period of 12 months in addition to weekly Qigong sessions for 12 months. No significant differences between treatment groups were detected. 
Table 1. Summary of study characteristics.

\begin{tabular}{|c|c|c|c|c|c|c|}
\hline Authors & Country & Setting & Sample & Design & Follow-up & Main findings \\
\hline $\begin{array}{l}\text { Bakker et al. } \\
(2007)\end{array}$ & $\begin{array}{l}\text { The } \\
\text { Netherlands }\end{array}$ & Primary care & $\begin{array}{l}\text { Patients with stress- } \\
\text { related mental disorder }(\mathrm{N} \\
=433)\end{array}$ & $\begin{array}{l}\text { Cluster-RCT with } 2 \text { groups: (i) treatment as usual (TAU); } \\
\text { (ii) a minimal intervention for stress-related mental } \\
\text { disorders delivered by GPs. }\end{array}$ & $\begin{array}{l}2,6,12 \\
\text { months }\end{array}$ & $\begin{array}{l}\text { No superior effect of the } \\
\text { minimal intervention } \\
\text { was observed. }\end{array}$ \\
\hline $\begin{array}{l}\text { Blonk et al. } \\
(2006)\end{array}$ & $\begin{array}{l}\text { The } \\
\text { Netherlands }\end{array}$ & $\begin{array}{l}\text { Primary } \\
\text { care/workplace }\end{array}$ & $\begin{array}{l}\text { Patients with work-related } \\
\text { psychological complaints } \\
(\mathrm{N}=82)\end{array}$ & $\begin{array}{l}\text { RCT with } 3 \text { groups: (i) TAU (i.e. two brief sessions with a } \\
\text { general practitioner); (ii) individual intervention delivered } \\
\text { by psychotherapists; (iii) individual intervention plus } \\
\text { advice from labour experts. }\end{array}$ & 4,10 months & $\begin{array}{l}\text { A significant effect of } \\
\text { the combined } \\
\text { intervention on full } \\
\text { RTW was found. }\end{array}$ \\
\hline $\begin{array}{l}\text { Eklund \& } \\
\text { Erlandsson } \\
(2011)\end{array}$ & Sweden & Primary care & $\begin{array}{l}\text { Patients with stress- } \\
\text { related disorders }(\mathrm{N}=84)\end{array}$ & $\begin{array}{l}\text { Non-randomised controlled trial with a matched control } \\
\text { group: (i) a matched comparison group selected from the } \\
\text { Social Insurance Office's (SIO) registry who received TAU } \\
\text { (e.g. follow-up meetings with SIO representative, contact } \\
\text { with employer, additional support); (ii) a group-based } \\
\text { intervention delivered by occupational therapists plus a 6- } \\
\text { week work placement. }\end{array}$ & 6,12 months & $\begin{array}{l}\text { A superior effect of the } \\
\text { group-based } \\
\text { intervention on full } \\
\text { RTW was observed. }\end{array}$ \\
\hline $\begin{array}{l}\text { Lander et al. } \\
(2009)\end{array}$ & Denmark & Primary care & $\begin{array}{l}\text { Patients with stress- } \\
\text { related disorders }(\mathrm{N}= \\
161)\end{array}$ & $\begin{array}{l}\text { Non-randomised controlled trial with a matched control } \\
\text { group: (i) TAU; (ii) individual consultation with a trained } \\
\text { psychologist and a social worker. }\end{array}$ & 17 months & $\begin{array}{l}\text { No significant effect of } \\
\text { the intervention on full } \\
\text { RTW was observed. }\end{array}$ \\
\hline $\begin{array}{l}\text { Netterstrøm et } \\
\text { al. (2013) }\end{array}$ & Denmark & Primary care & $\begin{array}{l}\text { Patients with stress } \\
\text { symptoms }(\mathrm{N}=140)\end{array}$ & $\begin{array}{l}\text { RCT with } 3 \text { groups: (i) wait-list control group; two thirds of } \\
\text { participants reported consulting with a psychologist or } \\
\text { general practitioner during the waiting period; (ii) TAU; } \\
\text { (iii) an individual stress management intervention plus a } \\
\text { mindfulness-based stress reduction (MBSR) course } \\
\text { delivered in groups. }\end{array}$ & $\begin{array}{l}\text { Post- } \\
\text { intervention }\end{array}$ & $\begin{array}{l}\text { A significant effect of } \\
\text { the intervention on full } \\
\text { RTW was observed. }\end{array}$ \\
\hline $\begin{array}{l}\text { Stenlund et al. } \\
\text { (2009) }\end{array}$ & Sweden & $\begin{array}{l}\text { Stress } \\
\text { clinic/university } \\
\text { hospital }\end{array}$ & $\begin{array}{l}\text { Patients with stress- } \\
\text { related disease and } \\
\text { burnout }(\mathrm{N}=136)\end{array}$ & $\begin{array}{l}\text { RCT with } 2 \text { groups: (i) qigong and work rehabilitation } \\
\text { support; (ii) a group-based cognitively oriented behavioural } \\
\text { rehabilitation programme. }\end{array}$ & 6,12 months & $\begin{array}{l}\text { No significant } \\
\text { difference in treatment } \\
\text { efficacy between groups } \\
\text { was observed. }\end{array}$ \\
\hline $\begin{array}{l}\text { Willert et al. } \\
(2011)\end{array}$ & Denmark & $\begin{array}{l}\text { Stress } \\
\text { clinic/university } \\
\text { hospital }\end{array}$ & $\begin{array}{l}\text { Patients with work-related } \\
\text { stress }(\mathrm{N}=102)\end{array}$ & $\begin{array}{l}\text { RCT with } 2 \text { groups: (i) wait-list control group; (ii) a group- } \\
\text { based stress management intervention delivered by } \\
\text { psychologists. }\end{array}$ & $\begin{array}{l}4,8,12 \\
\text { months }\end{array}$ & $\begin{array}{l}\text { A superior effect of the } \\
\text { intervention on full } \\
\text { RTW was observed. }\end{array}$ \\
\hline
\end{tabular}


Table 2. Summary of participant and intervention characteristics.

\begin{tabular}{|c|c|c|c|c|c|}
\hline \multirow[b]{2}{*}{ Authors } & \multicolumn{3}{|c|}{ Participant characteristics } & \multicolumn{2}{|l|}{ Intervention characteristics } \\
\hline & $\begin{array}{l}\text { Mean age in } \\
\text { years }(S D)\end{array}$ & $\begin{array}{l}\text { Female } \\
(\%)\end{array}$ & Level of education (\%) & Content & Duration \& Intensity \\
\hline $\begin{array}{l}\text { Bakker et } \\
\text { al. (2007) }\end{array}$ & $\begin{array}{l}\text { I: } 41.97 \text { (8.8); } \\
\text { C: } 39.5(9.6)\end{array}$ & $\begin{array}{l}\text { I: } 55 \% ; \\
\text { C: } 65 \%\end{array}$ & $\begin{array}{l}\text { I: low }=26 \%, \\
\text { intermediate }=42 \%, \text { high } \\
=31 \% ; \text { C: low }=22 \%, \\
\text { intermediate }=50 \%, \text { high } \\
=28 \%\end{array}$ & Advice on the content of functional rehabilitation. & $\begin{array}{l}\text { Whenever participating } \\
\text { patients visited their GP }\end{array}$ \\
\hline $\begin{array}{l}\text { Blonk et al. } \\
\text { (2006) }\end{array}$ & $42.0(7.9)$ & $19 \%$ & $\begin{array}{l}\text { Low }=26 \%, \text { intermediate } \\
=40 \%, \text { high }=15 \%\end{array}$ & $\begin{array}{l}\text { (ii) Individual stress management intervention based on CBT, focusing on psychoeducation on } \\
\text { work stress, registration of symptoms and situations, relaxation and time management; (iii) A } \\
\text { combination of the individual stress management intervention and advice from labour experts } \\
\text { on how to lower the workload and job demands and increase decision latitude. }\end{array}$ & 11 sessions \\
\hline $\begin{array}{l}\text { de Vente et } \\
\text { al. (2008) }\end{array}$ & $\begin{array}{l}\text { I: } 41.6(9.4) \text {; } \\
\text { C: } 40.9(9.6)\end{array}$ & $\begin{array}{l}\text { I: } 39 \% \\
\text { C: } 35 \%\end{array}$ & - & $\begin{array}{l}\text { (ii) A group-based stress management intervention based on CBT. Specific techniques } \\
\text { included psychoeducation, cognitive restructuring, time management, assertiveness skills, } \\
\text { relapse prevention and progressive muscle relaxation; (iii) An individual version of the same } \\
\text { stress management intervention. }\end{array}$ & 12 1-hour sessions \\
\hline $\begin{array}{l}\text { Eklund \& } \\
\text { Erlandsson } \\
\text { (2011) }\end{array}$ & $\begin{array}{l}\text { I: } 45.0(19.0) \text {; } \\
\text { C: } 46.0(9.0)\end{array}$ & $\begin{array}{l}\text { I: } 100 \% \\
\text { C: } 100 \%\end{array}$ & $\begin{array}{l}\text { I: university degree }= \\
40 \% ; C: \text { university } \\
\text { degree }=51 \%\end{array}$ & $\begin{array}{l}\text { A group-based intervention focusing on occupational self-analysis, goal setting and strategies } \\
\text { for accomplishing desired changes in the patterns of everyday activities, in addition to a work } \\
\text { placement. The intervention highlighted patients' total pattern of daily activities and the } \\
\text { balance between these. }\end{array}$ & $\begin{array}{l}\text { Two } 2.5 \text {-hour sessions } \\
\text { per week for } 10 \text { weeks; a } \\
\text { 6-week work placement }\end{array}$ \\
\hline $\begin{array}{l}\text { Lander et } \\
\text { al. }(2009)\end{array}$ & $\begin{array}{l}\text { I: } 42.9(8.6) ; \\
\text { C: } 43.1(8.4)\end{array}$ & $\begin{array}{l}\text { I: } 80.6 \% \text {; } \\
\text { C: } 83.2 \%\end{array}$ & $\begin{array}{l}\text { I: low }=58.3 \% ; C: \text { low }= \\
52.8 \%\end{array}$ & Individual intervention focusing on psychoeducation and problem-solving. & $4-5$ sessions \\
\hline $\begin{array}{l}\text { Netterstrøm } \\
\text { et al. } \\
\text { (2013) }\end{array}$ & $\begin{array}{l}44.2(\text { range }= \\
25-68)\end{array}$ & $82.1 \%$ & Intermediate $=44 \%$ & $\begin{array}{l}\text { An individual stress management intervention focusing on the identification of stressors at } \\
\text { work and at home, coping strategies, restoring balance, identifying obstacles for RTW and } \\
\text { gradual increase in working hours. In addition to this, a workplace dialogue was advocated. } \\
\text { Patients were also offered a group-based mindfulness-based stress reduction (MBSR) course. }\end{array}$ & $\begin{array}{l}\text { Eight 1-hour sessions } \\
\text { spread over } 12 \text { weeks; } \\
\text { eight weekly 2-hour } \\
\text { MBSR sessions }\end{array}$ \\
\hline $\begin{array}{l}\text { Stenlund et } \\
\text { al. (2009) }\end{array}$ & $\begin{array}{l}\text { I: } 40.9(7.1) \text {; } \\
\text { C: } 42.3(7.8)\end{array}$ & $\begin{array}{l}\text { I: } 73 \% \\
\text { C: } 68 \%\end{array}$ & $\begin{array}{l}\text { I: university degree }= \\
52 \% ; C: \text { university } \\
\text { degree }=48 \%\end{array}$ & $\begin{array}{l}\text { A group-based cognitively oriented behavioural rehabilitation programme focusing on } \\
\text { psychoeducation, self-talk, development of behavioural/cognitive/emotional skills and spiritual } \\
\text { issues and life values. In addition to this, patients were offered a course in Qigong, which } \\
\text { focused on balance, breathing, relaxation and mindfulness meditation. }\end{array}$ & $\begin{array}{l}\text { 30 3-hour sessions spread } \\
\text { over } 12 \text { months; Qigong } \\
\text { once weekly for } 12 \\
\text { months }\end{array}$ \\
\hline $\begin{array}{l}\text { Willert et } \\
\text { al. (2011) }\end{array}$ & $\begin{array}{l}\text { I: } 44.0(\text { range } \\
=28-61) ; \mathrm{C}: \\
46.0(\text { range }= \\
24-58)\end{array}$ & $\begin{array}{l}\text { I: } 80.4 \% \text {; } \\
\text { C: } 84.3 \%\end{array}$ & $\begin{array}{l}\text { I: short }=35.3 \%, \text { medium } \\
=54.9 \%, \text { long }=9.8 \% ; \mathrm{C}: \\
\text { short }=27.5 \% \text {, medium }= \\
56.9 \%, \text { long }=13.7 \%\end{array}$ & $\begin{array}{l}\text { A group-based CBT-based stress management intervention focused on psychoeducation, } \\
\text { identifying and modifying dysfunctional thinking, communication skills training and } \\
\text { implementing strategies at work. }\end{array}$ & $\begin{array}{l}83 \text {-hour sessions spread } \\
\text { over } 12 \text { weeks }\end{array}$ \\
\hline
\end{tabular}




\section{Publication bias}

Funnel plots with $95 \%$ confidence intervals (CIs) for the two meta-analyses conducted are depicted in Figure 2. Due to the limited number of studies, it is not possible to draw any firm conclusions regarding publication bias. However, both plots show some asymmetry, suggesting that studies reporting statistically significant treatment effects might have been favoured over studies with non-significant results.

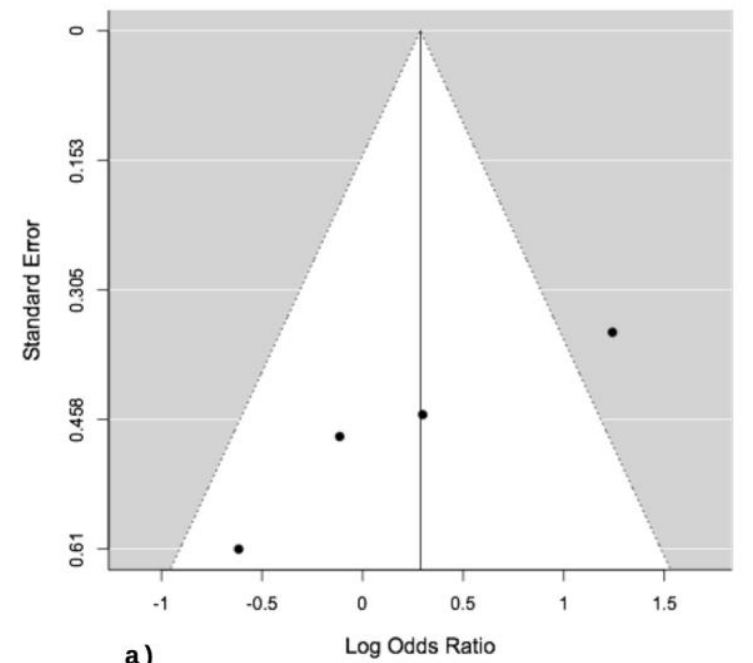

a)

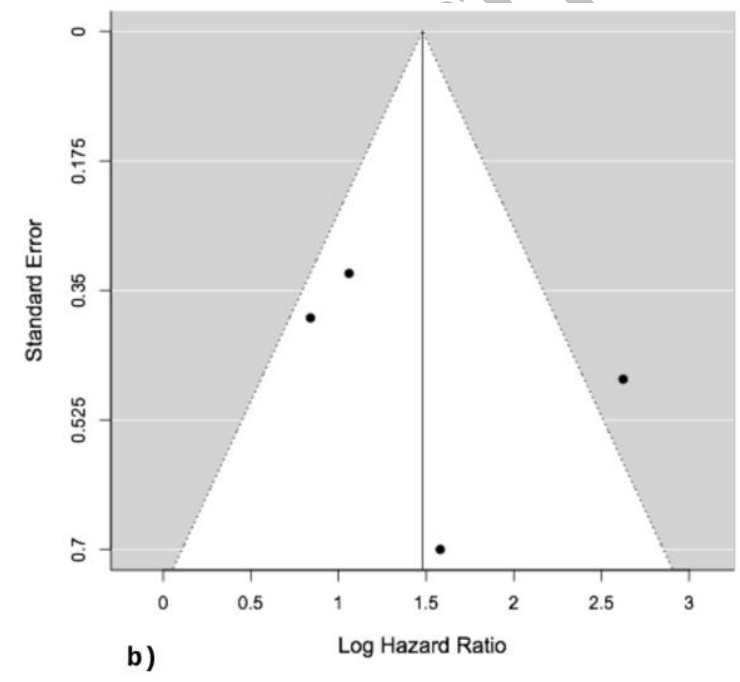

b)

Figure 2. Funnel plots of studies included in the meta-analysis. Panel a) displays studies assessing the effect of tertiary interventions on full RTW $(n=4)$; panel b) displays studies assessing the effect of tertiary interventions on time until RTW $(n=4)$.

\section{Study quality}

Several of the quality domains were rated as unclear across the included studies due to a lack of clarity in the reporting. Five of the included studies were rated as having low risk of bias with regards to random sequence generation. Allocation concealment was generally unclear or at high risk of bias, as was blinding of both participants/personnel and outcome assessors. Evidence of selective reporting was identified in three of the included studies (see Figure 3). 


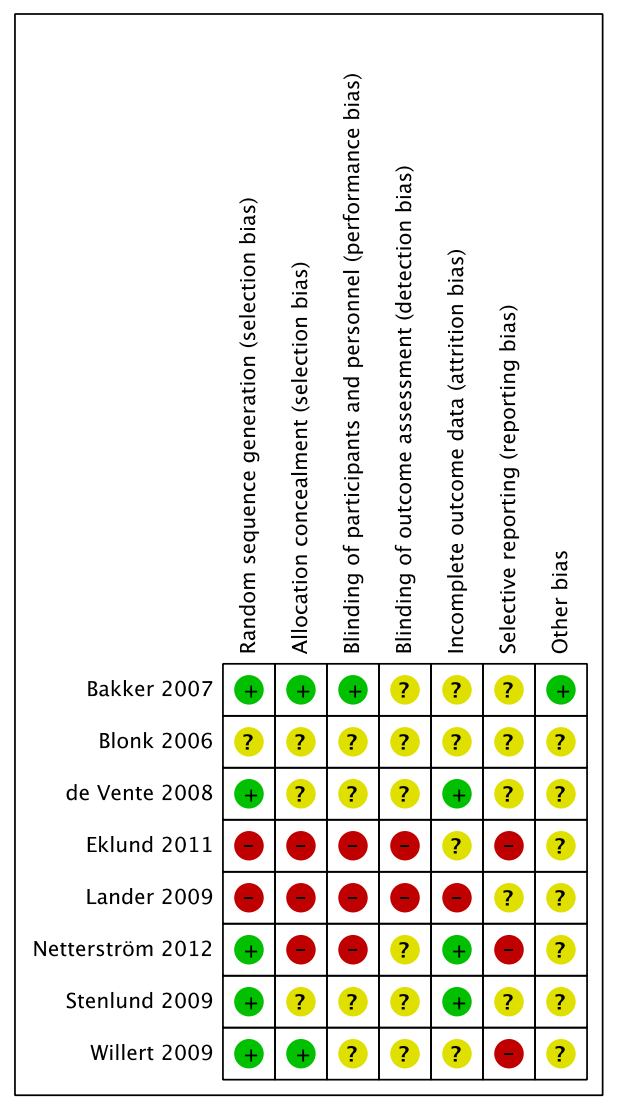

Figure 3. Summary of risk of bias.

\section{Study outcomes}

Full return-to-work. A random-effects model of studies comparing a tertiary intervention with TAU or wait-list controls did not find a significant effect on full RTW, odds ratio $(\mathrm{OR})=$ $1.33,95 \%$ confidence interval $(C I)=0.59-2.98$ (see Figure 4 ). Significant heterogeneity was found in this analysis, $\mathrm{I}^{2}=69 \%, \chi^{2}(3)=9.54, p=0.02$.

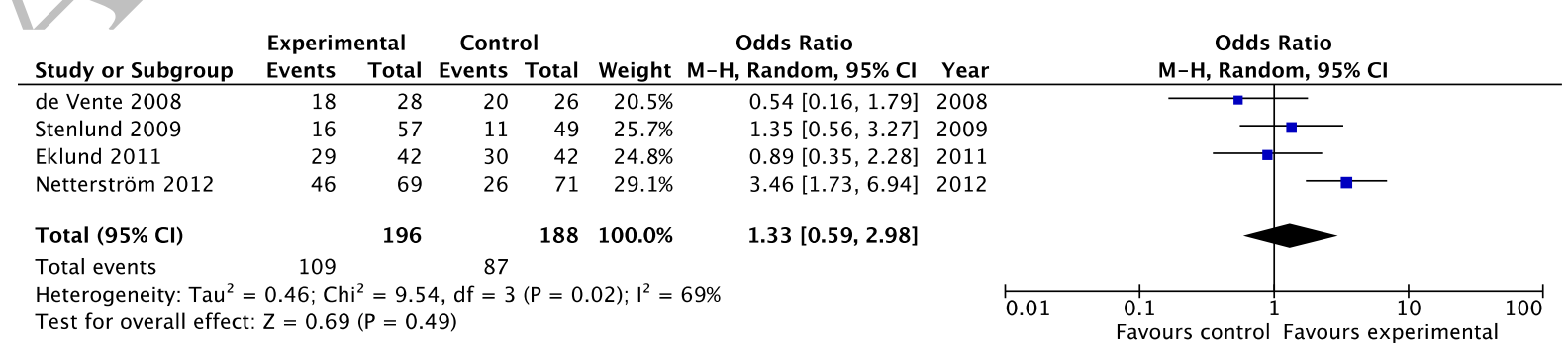


Figure 4. Meta-analysis of studies comparing the effect of a tertiary intervention with TAU or a wait-list control on full RTW for individuals with clinical burnout. Forest plot of ORs of full RTW in each study and total OR for all studies.

Time until return-to-work. A random-effects meta-analysis found a significant effect of tertiary interventions on time until RTW compared with TAU or wait-list controls, hazard ratio $(\mathrm{HR})=4.5,95 \% \mathrm{CI}=2.15-9.45$ (see Figure 5). However, significant heterogeneity wàs detected in this analysis, $\mathrm{I}^{2}=94 \%, \chi^{2}(3)=49.49, p<0.001$.

\begin{tabular}{|c|c|c|c|c|c|c|c|c|}
\hline Study or Subgroup & log[Hazard Ratio] & SE & Weight & $\begin{array}{c}\text { Hazard Ratio } \\
\text { IV, Random, 95\% Cl }\end{array}$ & Year & & $\begin{array}{l}\text { rd Ratio } \\
\text { om, 95\% Cl }\end{array}$ & \\
\hline Blonk 2006 & 2.623 & 0.221 & $25.9 \%$ & $13.78[8.93,21.25]$ & 2006 & & & - \\
\hline Bakker 2007 & 1.06 & 0.107 & $27.7 \%$ & $2.89[2.34,3.56]$ & 2007 & & - & \\
\hline Willert 2009 & 0.84 & 0.15 & $27.2 \%$ & $2.32[1.73,3.11]$ & 2009 & & -- & \\
\hline Lander 2009 & 1.58 & 0.49 & $19.2 \%$ & $4.85[1.86,12.68]$ & 2009 & & & \\
\hline Total $(95 \% \mathrm{Cl})$ & & & $100.0 \%$ & $4.50[2.15,9.45]$ & & & & \\
\hline \multicolumn{5}{|c|}{$\begin{array}{l}\text { Heterogeneity: } \mathrm{Tau}^{2}=0.50 ; \mathrm{Chi}^{2}=49.49, \mathrm{df}=3(\mathrm{P}<0.00001) ; \mathrm{I}^{2}=94 \% \\
\text { Test for overall effect: } \mathrm{Z}=3.98(\mathrm{P}<0.0001)\end{array}$} & 0.01 & $\begin{array}{l}1 \\
0.1 \\
\text { Favou }\end{array}$ & 1 Favours & $\begin{array}{l}1 \\
10 \\
\text { sperimental }\end{array}$ \\
\hline
\end{tabular}

Figure 5. Meta-analysis of studies comparing the effect of a tertiary intervention with TAU or a wait-list control on time until RTW for individuals with clinical burnout. Forest plot of HRs of time until RTW in each study and total HR for all studies.

\section{Secondary outcomes}

Exhaustion. Three studies assessed the effect of a tertiary intervention on exhaustion, a diagnostic criterion for clinical burnout. None of the studies found a significant effect, SMD = $0.01,95 \% \mathrm{CI}=-0.37-0.38$ (see Figure 6 ). As the aggregated sample size was small, the power to detect an effect was limited.

\begin{tabular}{|c|c|c|c|c|c|c|c|c|c|c|c|}
\hline \multirow[b]{2}{*}{ Study or Subgroup } & \multicolumn{3}{|c|}{ Experimental } & \multicolumn{3}{|c|}{ Control } & \multicolumn{3}{|c|}{ Std. Mean Difference } & \multirow{2}{*}{\multicolumn{2}{|c|}{$\begin{array}{l}\text { Std. Mean Difference } \\
\text { IV, Random, } 95 \% \mathrm{CI}\end{array}$}} \\
\hline & Mean & SD & Total & Mean & SD & Total & Weight & IV, Random, $95 \% \mathrm{CI}$ & Year & & \\
\hline Blonk 2006 & 3.5 & 1.6 & 40 & 3 & 1.8 & 42 & $33.0 \%$ & $0.29[-0.14,0.73]$ & 2006 & 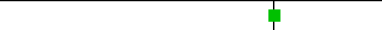 & \\
\hline de Vente 2008 & 2.69 & 1.65 & 28 & 2.53 & 1.52 & 26 & $27.0 \%$ & $0.10[-0.43,0.63]$ & 2008 & $\phi$ & \\
\hline Stenlund 2009 & 4 & 1.3 & 67 & 4.4 & 1.4 & 69 & $40.0 \%$ & $-0.29[-0.63,0.04]$ & 2009 & 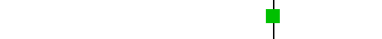 & \\
\hline Total $(95 \% \mathrm{Cl})$ & & & 135 & & & 137 & $100.0 \%$ & $0.01[-0.37,0.38]$ & & & \\
\hline \multicolumn{12}{|c|}{ 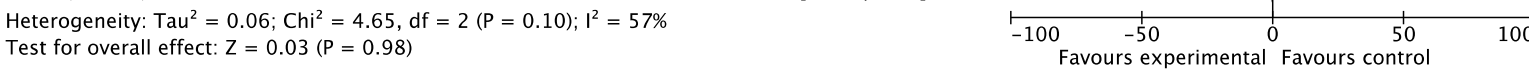 } \\
\hline
\end{tabular}


Figure 6. Meta-analysis of studies comparing the effect of a tertiary intervention with TAU or a wait-list control on exhaustion for individuals with clinical burnout. Forest plot of SMDs of exhaustion in each study and total SMD for all studies.

Depression. Four studies assessed the effect of a tertiary intervention on symptoms of depression. None of the studies found a significant effect of the intervention compared with TAU or a wait-list control, $\mathrm{SMD}=-0.11,95 \% \mathrm{CI}=-0.25-0.04$ (see Figure 7).

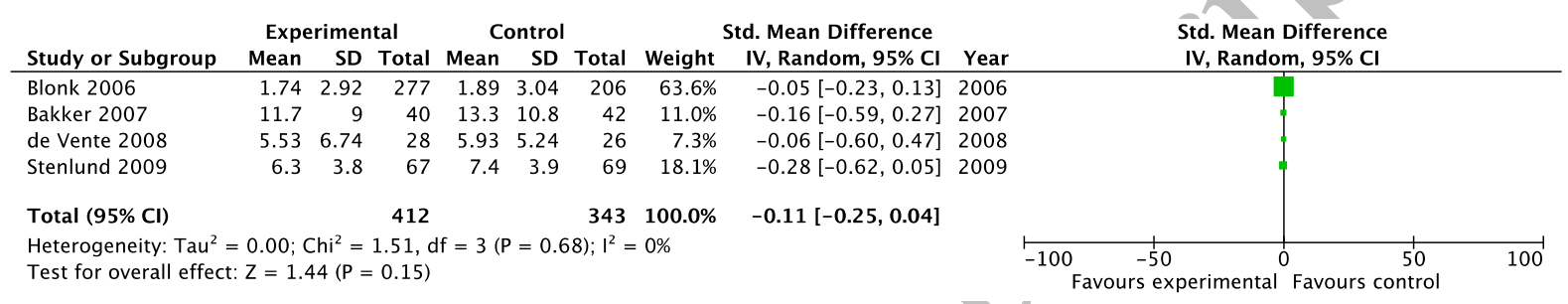

Figure 7. Meta-analysis of studies comparing the effect of a tertiary intervention with TAU or a wait-list control on depression for individuals with clinical burnout. Forest plot of SMDs of depression in each study and total SMD for all studies.

Anxiety. Four studies assessed the effect of a tertiary intervention on symptoms of anxiety with none of the studies detecting a significant effect, $\mathrm{SMD}=-0.04,95 \% \mathrm{CI}=-0.19-0.11$ (see Figure 8).

\begin{tabular}{|c|c|c|c|c|c|c|c|c|c|}
\hline \multirow[b]{2}{*}{ Study or Subgroup } & \multicolumn{3}{|c|}{ Experimental } & \multicolumn{3}{|c|}{ Control } & \multicolumn{3}{|c|}{ Std. Mean Difference } \\
\hline & Mean & SD & Total & Mean & SD & Total & Weight & IV, Random, $95 \% \mathrm{CI}$ & Year \\
\hline Blonk 2006 & 2.83 & 4.55 & 227 & 3.14 & 4.54 & 206 & $61.4 \%$ & $-0.07[-0.26,0.12]$ & 2006 \\
\hline Bakker 2007 & 8.6 & 7.3 & 40 & 7.1 & 7.2 & 42 & $11.6 \%$ & $0.20[-0.23,0.64]$ & 2007 \\
\hline de Vente 2008 & 5.53 & 6.19 & 28 & 5.31 & 6.68 & 26 & $7.7 \%$ & $0.03[-0.50,0.57]$ & 2008 \\
\hline Stenlund 2009 & 7.4 & 3.1 & 67 & 7.9 & 3.9 & 69 & $19.3 \%$ & $-0.14[-0.48,0.20]$ & 2009 \\
\hline Total $(95 \% \mathrm{Cl})$ & & & 362 & & & 343 & $100.0 \%$ & $-0.04[-0.19,0.11]$ & \\
\hline
\end{tabular}

Std. Mean Difference
IV, Random, $95 \% \mathrm{Cl}$


Figure 8. Meta-analysis of studies comparing the effect of a tertiary intervention with TAU or a wait-list control on anxiety for individuals with clinical burnout. Forest plot of SMDs of anxiety in each study and total SMD for all studies.

\section{Discussion}

The purpose of this systematic review and meta-analysis was to summarise and evaluate literature on the effectiveness of tertiary interventions for individuals with clinically significant burnout on RTW and psychological symptoms. The effectiveness of interventions was operationalised in terms of days until RTW, full RTW and a reduction in symptoms of exhaustion, anxiety and depression, respectively. A significant effect of tertiary interventions, as compared with TAU or wait-list controls, in facilitating days until RTW was observed. However, this finding should be interpreted with caution due to the detection of significant heterogeneity. No significant effect of interventions was found in terms of full RTW. Contrary to expectations, all studies showed that any reduction in psychological symptoms was comparable across conditions, irrespective of treatment assignment. Although it might be predicted that interventions focusing on RTW should also alleviate psychological symptoms, the available/data do not appear to support this notion.

Clinical observations indicate that patients with clinical burnout are often perfectionistic, intensely ambitious, overly committed to work and other chores and tend to relapse if their behavioral patterns remain unaltered (Maslach, Schaufeli, \& Leiter, 2001). To achieve successful RTW, patients must adopt behavioral patterns that facilitate the balance between activity and restitution, as well as a reasonable total workload. To this end, the involvement of employers and labour experts is particularly important, especially with regards to the modification of work-related tasks and a gradual increase in working hours. In line with this, Blonk, Brenninkmeijer, Lagerveld and Houtman (2006) and 
Eklund and Erlandsson (2011) found that advice from labour experts and gradual training in the workplace significantly increased rates of full RTW. The intervention by Netterstrøm, Friebel and Ladegaard (2013) did not only include stress management techniques, but also included dialogue with the employer and job redesign when needed. Tangible help with the planning of and gradual introduction to the resumption of work under the supervision of labour experts may thus be an effective intervention strategy. However, Willert, Thulstrup, and Bonde (2011) demonstrated successful RTW without explicitly using such methods. In this study, which aimed to increase patients' capacity to manage work stressors and stay active despite the presence of stress symptoms, participants were trained by psychologists to use CBT techniques (i.e. psychoeducation, modification of thinking patterns) in the work setting. Since approximately $50 \%$ of participants in this study was working to some extent, patients had the opportunity to practice their new coping skills in the workplace between therapy sessions. It is hence possible that the acquisition of new skills (e.g. stress management, activity pacing) may facilitate RTW if patients have the opportunity to practice implementing these in the work setting. In the study by Eklund and Erlandsson (2011), female patients on sick-leave due to stress-related disorders were trained to redesign daily occupations, a method that includes elements of pacing, planning of activities and restitution, and that is applied holistically to an individual's total pattern of daily activities. Using this method, intervention participants achieved greater balance between activities and restitution, both at work and in the private sphere, and were better able to resume work.

A lack of difference in symptom reduction across treatment arms has been observed in other intervention studies within this patient population (Netterstrøm et al., 2013; Perski \& Grossi, 2004). One possible explanation is that patients allocated to control groups spontaneously seek complementary treatment during the control period. For example, in the study by Netterstrøm et al. (2012), as many as two thirds of participants in the wait-list 
control group sought help from psychologists or physicians during the wait-list period.

Similar observations have been made by others: in a Swedish study, 29 of 40 patients $(73 \%)$ on the waiting list sought external treatment during the control period, thus improving their SMBQ scores to levels comparable to those in the intervention arm (Perski \& Grossi, 2004). As the natural course of clinical burnout is largely unexplored, it is currently unclear whether improvements observed in control groups may be reflective of spontaneous remission. However, as exhaustion disorder and adjustment disorder, which are conceptually equiyalent to clinical burnout, are considered to be chronic conditions, spontaneous remission within a few weeks without treatment is thus unlikely. Consistent with this argument, the 11 control patients in the study by Perski and Grossi (2004) who did not seek additional treatment did not exhibit significant change in their SMBQ scores over time. The extent to which control participants seek external treatment should thus be monitored, and statistically adjusted for, in future intervention studies within this patient population.

Another possible explanation for the lack of a difference in symptom reduction across intervention arms might be due to the presence of effective techniques in the TAU control conditions; additional techniques employed in the intervention conditions may not have contributed to greater reductions in psychological symptoms. Finally, follow-up periods of sufficient length may be required for effects of interventions to become apparent. For example, Stenlund et al. (2009) did not detect any significant differences in psychological symptoms between patients randomised to Qigong and CBT versus Qigong alone at either 6or 12-month follow-up. However, at three-year follow-up, participants in the combined intervention reported significantly decreased symptoms of burnout and higher rates of perceived recovery. They also reported greater use of cognitive techniques from the programme and decreased use of antidepressants in comparison with participants in the control condition (Stenlund, Nordin, \& Järvholm, 2012). 
It may also be argued that the assessment of psychological symptoms alone is an insufficient measure of intervention effectiveness. Clinical observations indicate that whilst many patients are able to return to work and live reasonably active lives despite residual symptoms of exhaustion, others become incapacitated at an equivalent or even lower symptom load (Perski \& Grossi, 2004). Hence, the extent to which individual differences in symptom perception and adaptation influence RTW and the ability to lead an active life constitutes an important avenue for future research.

The present review has several strengths. The search strategy, article screening, data extraction and data synthesis were guided by recommendations from the Cochrane Collaboration (2011). Study quality was determined based on key aspects of methodological rigour (e.g. concealed treatment allocation, blinded assessors). This is an important consideration, as studies affected by methodological biases may exaggerate treatment effects. We also explored the possibility of publication bias through the generation of funnel plots, which indicated that studies reporting statistically significant treatment effects might have been favoured over studies with non-significant results. However, due to the small number of included studies, we did not formally assess publication bias through, for example, a rank correlation test. We can hence not eliminate the subjectivity inherent in the visual inspection of funnel plot asymmetry (Lau, Ioannidis, Terrin, Schmid, \& Olkin, 2006).

This review also has several limitations. The small number of studies eligible for inclusion did not allow us to perform sensitivity analyses of the differential effectiveness of intervention subtypes. Further research is needed to identify specific intervention components (e.g. employer support, cognitive restructuring) that are effective in facilitating RTW. In addition, the extent to which treatment intensity (i.e. number of sessions per week), duration (i.e. total length of treatment), delivery mode (i.e. individual versus group treatment) and who 
the intervention is delivered by (e.g. a trained psychologist versus a GP) may influence outcomes constitute important avenues for future research. Another limitation of this review is the lack of reporting of concurrent treatment amongst control group participants in the included studies. We are currently unable to rule out the possibility that additional, unreported support was sought by a significant proportion of control group participants and hence, that this may have affected effect sizes. Another potential limitation concerns the search strategy used; due to the lack of consensus regarding the terminology surrounding the diagnosis of interest, we used a broad range of search terms including 'clinical burnout', 'exhaustion disorder', 'adjustment disorder' and 'stress-related mental disorder' to increase the possibility of finding all relevant trials on the topic. However, it is possible that additional trials have been missed.

In conclusion, tertiary interventions for individuals with clinical burnout may be effective in facilitating RTW. Successful interventions included advice from labour experts and enabled patients to initiate a workplace dialogue with their employers. More research is needed to evaluate the relative efficacy of specific intervention components.

\section{Conflict of Interest}

The authors have no conflicts of interest to declare. 


\section{References}

Ahola, K., Toppinen-Tanner, S., \& Seppänen, J. (2017). Interventions to alleviate burnout symptoms and to support return to work among employees with burnout: Systematic review and meta-analysis. Burnout Research, 4, 1-11.

http://doi.org/10.1016/j.burn.2017.02.001

Åsberg, M., Nygren, Å., \& Nager, A. (2013). Att skilja mellan depression och utmattningssyndrom. Läkartidningen, 110(9), 484-486.

Bakker, I. M., Terluin, B., van Marwijk, H. W. J., van der Windt, D. A. W. M., Rijmen, F., van Mechelen, W., \& Stalman, W. A. B. (2007). A cluster-randomised trial evaluating an intervention for patients with stress-related mental disorders and sick leave in primary care. PLoS Clinical Trials, 2(6), e26. http://doi.org/10.1371/journal.pctr.0020026

Bianchi, R., Sam, I., \& Laurent, E. (2015). Burnout - depression overlap: A review. Clinical Psychology Review, 36, 28-41. http://doi.org/10.1016/j.cpr.2015.01.004

Bjelland, I., Dahl, A. A., Haug, T. T., \& Neckelmann, D. (2002). The validity of the Hospital Anxiety and Depression Scale: An updated literature review. Journal of Psychosomatic Research, 52,69-77. http://doi.org/10.1016/S0022-3999(01)00296-3

Blonk, R. W. B., Brenninkmeijer, V., Lagerveld, S. E., \& Houtman, I. L. D. (2006). Return to work: A comparison of two cognitive behavioural interventions in cases of work-related psychological complaints among the self-employed. Work \& Stress: An International Journal of Work, Health \& Organisations, 20(2), 129-144.

http://doi.org/10.1080/02678370600856615

Centre for Reviews and Dissemination, U. of Y. (2008). Systematic Reviews: CRD's guidance for undertaking reviews in healthcare. (K. Khan, G. Ter Riet, J. Glanville, A. Sowden, \& 
J. Kleijnen, Eds.). Retrieved from http://eprints.whiterose.ac.uk/1139/

de Vente, W., Kamphuis, J. H., Emmelkamp, P. M. G., \& Blonk, R. W. B. (2008). Individual and group cognitive-behavioral treatment for work-related stress complaints and sickness absence: a randomized controlled trial. Journal of Occupational Health Psychology, 13(3), 214-231. http://doi.org/10.1037/1076-8998.13.3.214

Egger, M., Davey Smith, G., Schneider, M., \& Minder, C. (1997). Bias in meta-analysis detected by a simple, graphical test. British Medical Journal, 315(7109), 629-634. http://doi.org/10.1136/bmj.316.7129.469

Eklund, M., \& Erlandsson, L.-K. (2011). Return to Work Outcomes of the Redesigning Daily Occupations (ReDO) Program for Women with Stress-Related Disorders - A Comparative Study. Women \& Health, 51(7), 676-692. http://doi.org/10.1080/03630242.2011.618215

European Agency for Safety and Health at Work. (2014). Calculating the cost of work-related stress and psychosocial risks.

Franche, R.-L., Cullen, K., Clarke, J., Irvin, E., Sinclair, S., \& Frank, J. (2005). WorkplaceBased Return-to-Work Interventions : Journal of Occupational Rehabilitation, 15(4), 607-631.http://doi.org/10.1007/s10926-005-8038-8

Grossi, G., Perski, A., Osika, W., \& Savic, I. (2015). Stress-related exhaustion disorder clinical manifestation of burnout? A review of assessment methods, sleep impairments, cognitive disturbances, and neuro-biological and physiological changes in clinical burnout. Scandinavian Journal of Psychology, 56(6), 626-636. http://doi.org/10.1111/sjop.12251

Lander, F., Friche, C., Tornemand, H., Andersen, J. H., \& Kirkeskov, L. (2009). Can we 
enhance the ability to return to work among workers with stress-related disorders? $B M C$ Public Health, 9, 372. http://doi.org/10.1186/1471-2458-9-372

Lau, J., Ioannidis, J. P. A., Terrin, N., Schmid, C. H., \& Olkin, I. (2006). The case of the misleading funnel plot. BMJ, 333, 597-600. http://doi.org/10.1136/bmj.38946.501215.68

Leiter, M. P., \& Durup, J. (1994). The discriminant validity of burnout and depression: A confirmatory factor analytic study. Anxiety, Stress, \& Coping, 7, 357-373.

Maslach, C., \& Goldberg, J. (1998). Prevention of burnout: New perspectives. Applied \& Preventive Psychology, 7, 63-74. http://doi.org/10.1016/S0962-1849(98)80022-X

Maslach, C., Schaufeli, W. B., \& Leiter, M. P. (2001). Job burnout. Annual Review of Psychology, 52, 397-422. http://doi.org/10.1146/annurev.psych.52.1.397

Moher, D., Liberati, A., Tetzlaff, J., \& Altman, D. G. (2009). Preferred reporting items for systematic reviews and meta-analyses: the PRISMA statement. PLoS Medicine, 6(7), e1000097. http://doi.org/10.1371/journal.pmed.1000097

Montano, D., Hoven, H., \& Siegrist, J. (2014). Effects of organisational-level interventions at work on employees' health: a systematic review. BMC Public Health, 14(1), 9. http://doi.org/10.1186/1471-2458-14-135

Netterstrøm, B., Friebel, L., \& Ladegaard, Y. (2013). Effects of a multidisciplinary stress treatment programme on patient return to work rate and symptom reduction: Results from a randomised, wait-list controlled trial. Psychotherapy and Psychosomatics, 82, 177-186. http://doi.org/10.1159/000346369

OECD. (2012). Sick on the Job? Myths and Realities about Mental Health and Work.

OECD. (2013). Mental Health and Work: Sweden. 
Perski, A., \& Grossi, G. (2004). Behandling av långtidssjukskrivna patienter med stressdiagnoser: Resultat från en interventionsstudie. Läkartidningen, 101(14), 12951298.

Richardsen, A. M., Burke, R. J., Leiter, M. P., Richardsen, A. M., Burke, R. J., Leiter, M. P., ... Burke, R. J. (1992). Occupational demands, psychological burnout and anxiety among hospital personnel in Norway. Anxiety, Stress, \& Coping, 5(1), 55-68.

Richardson, K. M., \& Rothstein, H. R. (2008). Effects of occupational stress management intervention programs: A meta-analysis. Journal of Occupational Health Psychology, 13(1), 69-93. http://doi.org/10.1037/1076-8998.13.1.69

Ruddy, R., \& House, A. (2005). Psychosocial interventions for conversion disorder. The Cochrane Database of Systematic Reviews, (4), CD005331. http://doi.org/10.1002/14651858.CD005331.pub2

Schaufeli, W. B., Bakker, A. B., Hoogduin, K., Schaap, C., \& Kladler, A. (2001). On the Clinical Validity of the Maslach Burnout Inventory and the Burnout Measure. Psychology and Health, 16, 565-582. http://doi.org/10.1080/08870440108405527

Schutte, N., Toppinen, S., Kalimo, R., \& Schaufeli, W. B. (2000). The factorial validity of the Maslach Burnout Inventory-General Survey (MBI-GS) across occupational groups and nations. Journal of Occupational and Organizational Psychology, 73, 53-66. http://doi.org/10.1348/096317900166877

Shirom, A., \& Melamed, S. (2006). A comparison of the construct validity of two burnout measures in two groups of professionals. International Journal of Stress Management, 13(2), 176-200. http://doi.org/10.1037/1072-5245.13.2.176

Stenlund, T., Ahlgren, C., Lindahl, B., Burell, G., Steinholtz, K., Edlund, C., ... Slunga 
Birgander, L. (2009). Cognitively oriented behavioral rehabilitation in combination with qigong for patients on long-term sick leave because of burnout: REST - A randomized clinical trial. International Journal of Behavioral Medicine, 16, 294-303. http://doi.org/10.1007/s12529-008-9011-7

Stenlund, T., Nordin, M., \& Järvholm, L. S. (2012). Effects of rehabilitation programmes for patients on long-term sick leave for burnout: A 3-year follow-up of the rest study. Journal of Rehabilitation Medicine, 44(8), 684-690. http://doi.org/10.2340/165019771003

The Cochrane Collaboration. (2011). Cochrane Handbook for Systematic Reviews of Interventions Version 5.1.0. [Updated March 2011]. (J. Higgins \& S. Green, Eds.). Retrieved from www.cochrane-handbook.org

The Nordic Cochrane Centre: The Cochrane Collaboration. (2008). Review Manager (RevMan).

Thomson Reuters. (2013). EndNote X7. Philadelphia, USA.

van Oostrom, S. H., Driessen, M. T., De Vet, H. C. W., Franche, R.-L., Schonstein, E., Loisel, P., ... Anema, J. R. (2009). Workplace interventions for preventing work disability. Cochrane Database of Systematic Reviews, (2), CD006955.

Willert, M. V., Thulstrup, A. M., \& Bonde, J. P. (2011). Effects of a stress management intervention on absenteeism and return to work - results from a randomized wait-list controlled trial. Scandinavian Journal of Work Environment \& Health, 37(3), 186-195. http://doi.org/10.5271/sjweh.3130

Zigmond, A. S., \& Snaith, R. P. (1983). The Hospital Anxiety and Depression Scale. Acta Psychiatrica Scandinavica, 67(6), 361-370. http://doi.org/10.1111/j.1600- 
0447.1983.tb09716.x

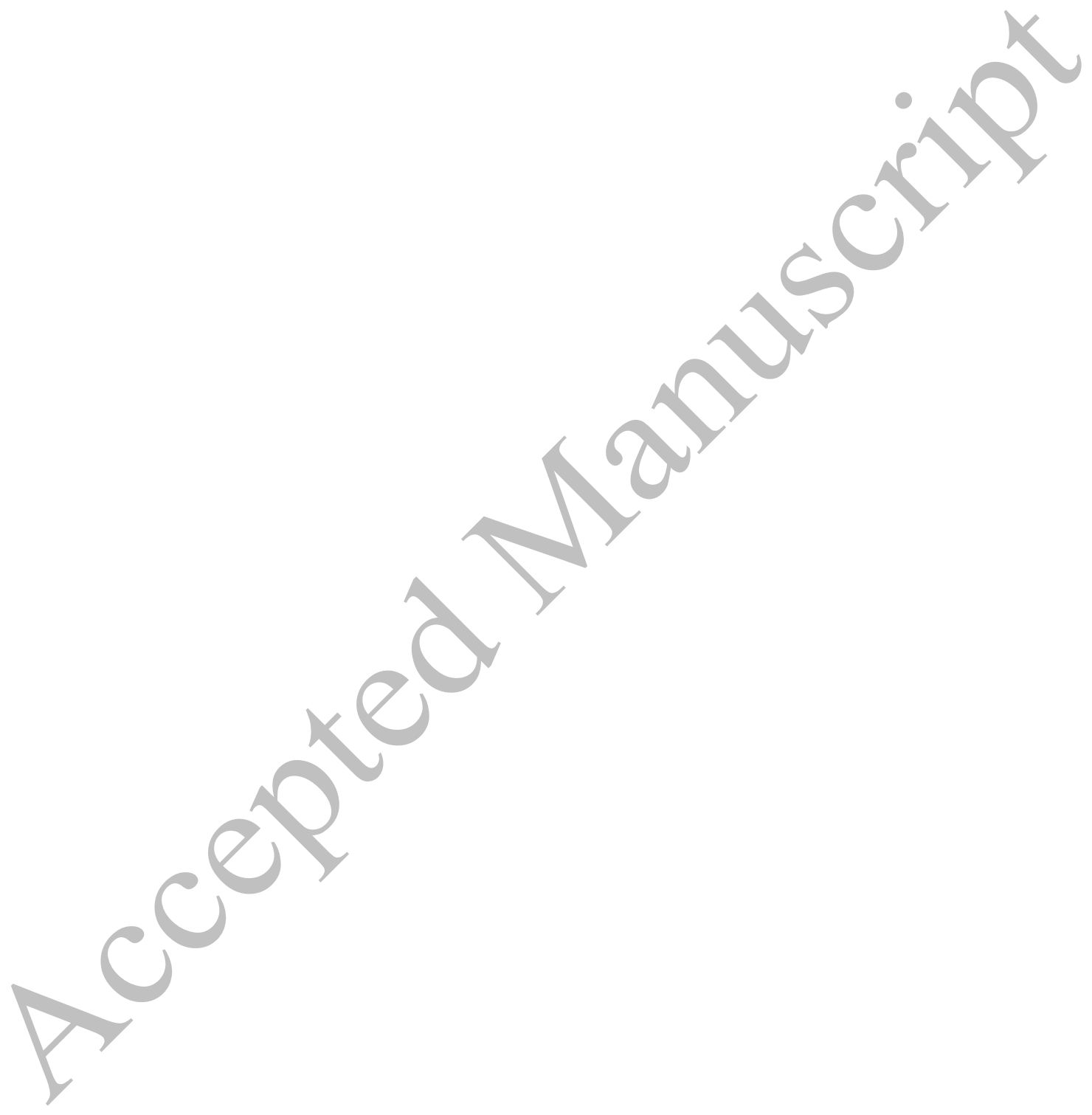

